\title{
The Impact of a Word of Mouth Mechanism on an Adoption of Changes in the Industrial Organization
}

\author{
By Agnieszka Kowalska-Styczeń*
}

In modern organizations, adaptation to the rapid changes in the market is a prerequisite to survival and growth. Many empirical studies have confirmed the assertion that employees' attitudinal and behavioural reactions to change play a major role in success or failure of changes in their organizations. In this study, the process of the spread of an information about change by word of mouth (w-o$m$ ) mechanism is presented. The effects of $w$-o-m mechanism on the change adoption is investigated, because this is a crucial tool in this sphere. The w-o-m communication has been supported by an external field (meetings, leaflets, etc.) and the leaders. Cellular automaton is used as a modelling tool, because it allows to analyse the dynamics of changes in views and attitudes in social groups based on local interactions between people in small informal groups. Informal groups of employees are represented by the von Neumann's neighbourhood of radius $r=1$ (4-element neighbourhood) and Moore's neighbourhood of radius $r=1$ (8-element neighbourhood). The employees' environment in the model is shown as a discrete twodimensional space, which consists of a finite square lattice of cells. Simulations were carried out for a different density of lattice. This possibility allows to take into account the natural fact, that informal groups have a different size, or a larger or smaller number of $w-o-m$ contacts. Precise results of experiments showed high usefulness of cellular automata approach in the discussed area.

\section{Introduction}

In modern organizations, adaptation to rapid changes in the market is a prerequisite to survival and growth. Many empirical studies have confirmed the assertion that employees' attitudinal and behavioural reactions to change, play a major role in success or failure of the changes in their organizations (e.g., Kotter and Cohen, 2002; Van Knippenberg et all, 2006; Whelan-Berry et all, 2003). In this change process, people hold an important place, because they are directly and indirectly affected by changes and as a consequence they react differently since each change causes emotional reactions (Tadarita, 2010). Simultaneously, the smooth adaptation of employees to changes contributes not

*Assistant Professor, The Silesian University of Technology, Poland. 
only to improved running of organizations but also to their personal improvement and an enhanced satisfaction. Introducing changes in organizations, it is important, to convince the community of employees to them.

Pugh (2003) suggests six rules for management, with the purpose of facilitating change. He points out, that the change should be initiated through informal communication and feed-back to ensure peoples' participation. Also Bernerth (2004) and Eby et all (2000) think, that the ability of an organization to change depends considerably on the openness, commitment, and motivation to change of its employees. According to Miller et all (1994), openness to the changes that are being proposed and implemented in an organization is a "necessary initial condition for successful planned change" (p. 60). Many researchers have examined the impact of various factors on openness to change (Bommer et all, 2005; Oreg, 2006; Devos et all, 2007). For example, Devos et all (2007) tested the impact of three factors on employees' openness to change: content, context, and process.

In this study, the process of the spread of an information about change by the word of mouth (w-o-m) mechanism is presented. The effects of the w-o-m mechanism on the change adoption is investigated, because this is a crucial tool in this sphere. Burt's results (2007) argue for the w-o-m communication, because, as a result of his research, indirect contacts have no meaning, but even in very various circumstances, an important role is played by the network of direct contacts. These contacts take place in informal groups within the organization (which are led or dominated by people with less formal authority within the organizational structure).

The proposed paper also shows the possibility of modelling the dynamics of conviction to change in the organization, if the basic assumption of this process is the presence of leaders and the their impact on the employees community opinion. The leaders (or agents of change - discussed by Hendrick and Kleiner (2001)), have greater power of persuasion with respect to other members of organization. Employees may be also persuaded to adopt the changes during special meetings, leaflets, etc. (in the model this is the external field of interactions). The cellular automaton is used as a modelling tool, because it allows to analyse the dynamics of changes in views and attitudes in social groups based on local interactions between people in small informal groups. Informal groups of employees are represented by the von Neumann's and Moore's neighbourhood for $\mathrm{r}=1$ (neighbourhood 4-element and neighbourhood 8-element). The employees' environment in the model is shown as a discrete two-dimensional space, which consists of a finite square lattice of cells.

The following sections discuss a model that allows simulate influence of the leaders of change (agents) on the process of changes in the views of members of the organization, and the results of simulation experiments are presented and discussed. 


\section{The Model}

In the model presented in this article, a two-dimensional CA is proposed with von Neumann's neighbourhood of radius $r=1$ (neighbourhood 4-element, Figure 1 - left panel) and Moore's neighbourhood of radius $r=1$ (neighbourhood 8-element, Figure 1 - right panel).

In this paper, the research concerns the behaviour of individuals forming an organization. The environment of agents/ employees in the model is presented as a square network of size $\mathrm{N}$ x $\mathrm{N}$ with periodic boundary conditions. Two situations with w-o-m communication are simulated. In the first case, in addition to $\mathrm{w}-\mathrm{O}-\mathrm{m}$ communication, the external field ' $\mathrm{m}$ ' convinces to adoption of changes. This field is equated with the ability to persuade employees to accept change during special meetings with them. In the second one, apart from the usual agents, some of them shall be the leaders who have greater power of persuasion.

Figure 1. Von Neumann's Neighbourhood of Radius $r=1$, 4-element Neighbourhood (left panel) and Moore's Neighbourhood of Radius $r=1$, 8-element Neighbourhood (right panel)
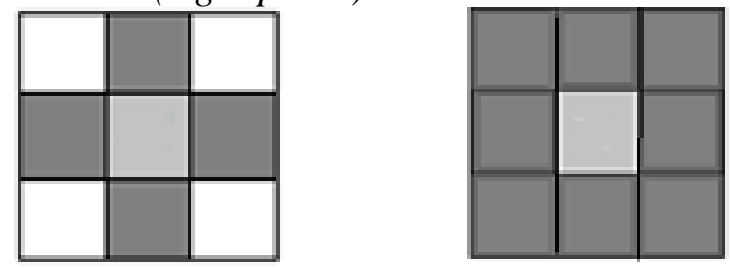

Each $i$-th cell $\left(i=1,2, \ldots, N^{2}\right)$ can be in one of three states: empty, occupied by an agent of type A or occupied by an agent of type B. In this paper, the cells occupied by the agents in lattice, correspond to employees. Type A is defined as employees who are in favour of adoption of changes, and $\mathrm{B}$ is defined as employees who are not. Initially agents are distributed randomly on the lattice, i.e. a cell is occupied with probability $p \in[0,1]$, and empty with probability $1-\mathrm{p}$.

In the first case, at each time step t, all cells are updated simultaneously (typical cellular automata approach, Wolfram, 1984, 2002) according to the following local rules:

- Agent checks the preferences of its neighbourhood and changes its preference for the dominant in the neighbourhood (ie., if more than $50 \%$ of its neighbours have a different opinion than him, then he changes his opinion to the dominant one).

- If more than $50 \%$ have the same opinion as the test agent, of course, nothing changes.

- Subsequently, the external field $m \in[0,1]$ works, so that $m \times 100$ percent randomly selected agents who were not opting for accepting the changes, are in favour of them now. 
- If there is no dominant preference in the agent neighbourhood and the agent did not change as a result of field m activity, the agent moves to the nearest empty place in a random direction (north, east, south and west).

In the second case, leaders convince to accept the changes. Due to the presence of agents and leaders in this model, and their unlike role, different rules of behaviour are proposed for them.

Rules for Agents:

- Agent checks the preferences of its neighbourhood and changes its preference for the dominant in the neighbourhood (ie., if more than $50 \%$ of its neighbours have a different opinion than him, then he changes his opinion on the dominant one).

- Agent also changes his preference when in its neighbourhood there is at least one leader

- If more than $50 \%$ have the same opinion as the test agent or there is no leader, of course, nothing changes.

- If there is no dominant preference in the agent neighbourhood, or a lack of leader, the agent moves to the nearest empty place in a random direction (north, east, south and west).

The rules for leaders

- If the agent is a leader even though he is in the middle cell, he does not change under the influence of environment and moves to the nearest empty place in a random direction.

Defining cellular automaton this way, effects of interpersonal influence (w-o-m communication), impact of action external field and persuasion power of leaders are taken into account. In order to make simulation experiments one should establish the size of $\mathrm{N}$ (which determines a number of society members), $r-a$ size of the neighbourhood and $p-$ population density. The introduction of various population density is a step in the direction of the approximation of the $\mathrm{CA}$ model to social reality, where the nearest neighbourhood, influencing decisions of individuals, consist of varied numbers of people (group of employees containing different number of members).

\section{Simulation Experiment}

\section{Design of Experiments}

In the simulations, the agents have a choice of two behaviour types. A - favours the adoption of changes, whereas B does not. Furthermore, it was assumed that at the beginning of the simulation all 'normal' agents prefer option B, leaders and these affected by an external field ' $m$ ' prefer A. 
Experiments that have been conducted here were designed to investigate the impact of the word of mouth mechanism on the adoption of changes. The parameters affecting the employee preferences change, forming the w-O-m mechanism, were changed by following independent variables:

- $\mathrm{p}$ - population density

- neighbourhood size

- agent movement possibility

- $\mathrm{m}$ - the intensity level of an external field

- 1 - the level of a leaders fraction

As the dependent variable describing an agents behaviour the average number of people choosing the A option (in favour of changes) was adopted. This average is calculated after 1000 simulations.

In the study, two levels of first three factors changes were assumed:

- $\mathrm{p}$ (population density): 0,5 and 0,8;

- $r$ - Von Neumann's neighbourhood of radius $r=1$ (4-element neighbourhood) and Moore's neighbourhood of radius $r=1$ (8element neighbourhood)

- possibility of agent with or without movement

The external field intensity level ' $m$ ' was changed from $1 \%$ to $20 \%$ with the step of $1 \%$. The leaders fraction level (opting for A) was changed from 5\% to $55 \%$ with the step of $5 \%$.

In the next section there is a discussion concerning the results of simulation.

\section{Simulation Results}

Initially, an analysis of the impact of the change of $\mathrm{m}$ - external field, which convinces employees to adoption of change was performed. It was established, that the external field works only for employees who are not convinced to accept changes. Population densities $\mathrm{p}=0,5$ and $\mathrm{p}=0,8$ were adopted, to see how the external field works in the network of sparser and denser ties between employees. This density allows consumers to move in the lattice, and at the same time there are many w-o-m contacts. Simulations have been carried out for the lattice size of $\mathrm{N}=10,20$ and 30. In this article the results for $\mathrm{N}=20$ are presented, but for $\mathrm{N}=10$ and $\mathrm{N}=30$ the same results have been obtained.

As can be seen in Figure 2 and 3, the external field is more effective in the case of a smaller density $(p=0,5)$. Less intense ' $m$ ' causes a bigger tendency to accept changes, than for $\mathrm{p}=0,8$. Moreover, for the sparser lattice, the $\mathrm{m}$ efficiency depends on the neighbourhood size. The larger number of contacts in the w-o-m mechanism, the grater effectiveness of external field. The results indicate the fact that changes in community opinion as a whole, do not depend on the agents movement. 
Figure 2. The change of the average concentration of A-agents, depending on the level of external field at the beginning of simulations, for $p=0,5$. The results are obtained for 4-elements and 8-elements neighbourhood and model with movement $-(\mathrm{m})$, model without movement - (wm)

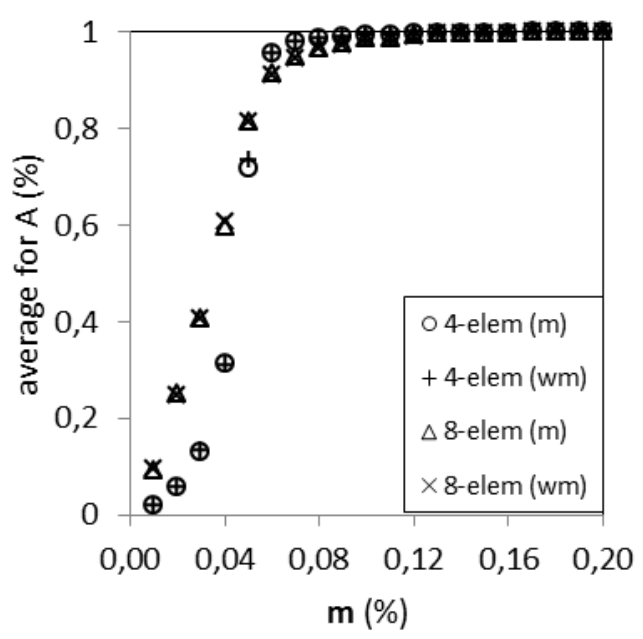

Figure 3. The change of the average concentration of A-agents, depending on the level of external field at the beginning of simulations, for $p=0,8$. The results are obtained for 4-elements and 8-elements neighbourhood and model with movement - $(\mathrm{m})$, model without movement - $(\mathrm{wm})$

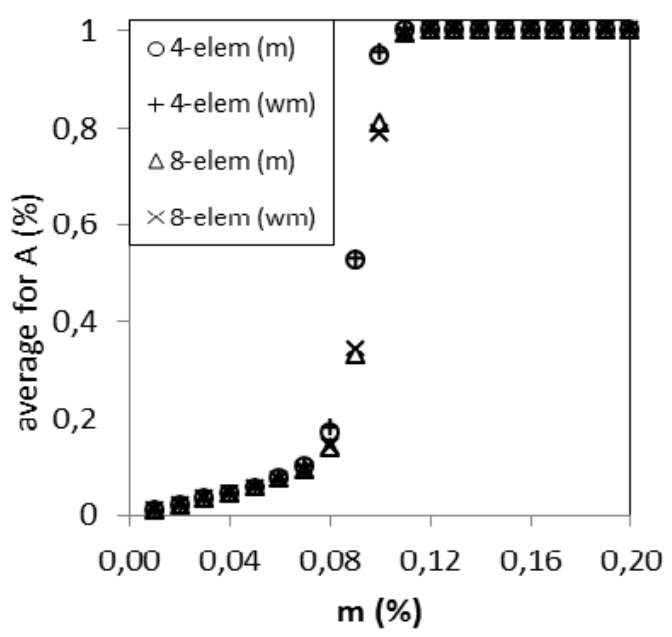

Subsequently, there has been an analysis on how the leaders affect the adoption of a change among employees. As mentioned above, population densities $p=0,5$ and $p=0,8$ have been adopted. Simulations have been carried out for the network size $\mathrm{N}=20$, because, as it was shown in Kowalska-Styczeń (2012), the size of the lattice does not affect the results. Figure 4 and 5 show the dynamics of preferences (average for adoption of change), depending on the percentage of leaders, for a different population density and neighbourhood, defined above. 
Figure 4. The change of the average concentration of A-agents, depending on the fraction of leaders at the beginning of simulations, for $p=0,5$. The results are obtained for 4-elements and 8-elements neighbourhood and model with movement - $(\mathrm{m})$, model without movement $-(\mathrm{wm})$

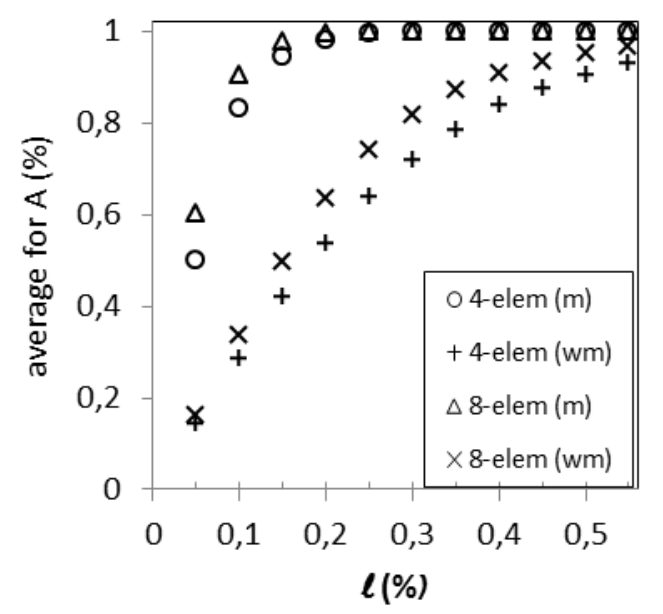

Figure 5. The change of the average concentration of A-agents, depending on the fraction of leaders at the beginning of simulations, for $p=0,7$. The results are obtained for 4-elements and 8-elements neighbourhood and model with movement - $(\mathrm{m})$, model without movement - $(\mathrm{wm})$

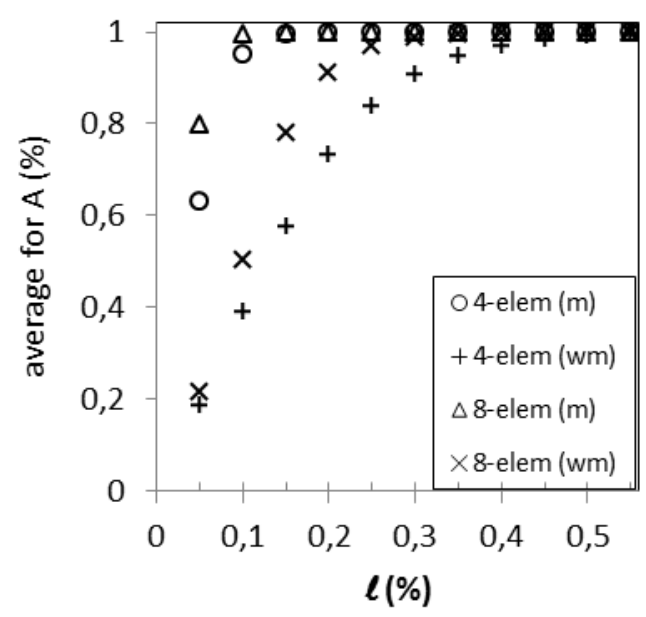

The results in Figure 4 and 5 show how the opinion changes in the organization depend on the population density, the neighbourhood size and agent movement. For denser network $(p=0,7)$ the complete conviction to change adoption is more possible along with the involvement of a smaller number of leaders, than for sparser network $(p=0,5)$. As can be seen in Figure 4 and 5, the possibility of obtaining complete conviction in the adoption of change involves a smaller number of leaders for larger informal groups (8elements neighbourhood). The neighbourhood size reflects the number of informal w-o-m contacts in groups of employees. 
The conviction to accept the changes is also modified by the possibility to consult the other sources of information (modelled by agent movement). The agents movement strongly increases the efficiency of leaders.

\section{Summary and Conclusion}

The purpose of this article was to examine the impact of the word of mouth communication on an adoption of changes in an industrial organization. Parameters affecting the w-o-m communications were modelled by the different neighbourhood size and the possibility of agents movement. The employees support is very important to adopt changes in the organization, so that the w-o-m communication relates to accepting the change. In this paper, the w-o-m communication has been supported by an external field (meetings, leaflets, etc. concerning the change adoption) and the leaders. Fleming at al. (2007) has shown in the context of changes in the organization, that the high level of consistency of the network increases the chance of adapting innovation, and a greater number of connections between 'agents', facilitates the exchange of knowledge. So here, the simulations have been performed for sparser $(\mathrm{p}=0,5)$ and denser $(\mathrm{p}=0,7)$ network. For $\mathrm{p}=0,5$, there are fewer connections between employees than for $\mathrm{p}=0,7$. Results of presented simulations generally supports the above conviction.

The obtained results additionally show, that the effect of the external field is more efficient for the sparser network, whereas the impact of leaders is stronger in the case of denser network of connections between employees. If the connections between employees are sparser, the w-o-m communication is less effective, thus meetings, leaflets, etc. give better results in conviction the employees to accept changes. For denser networks $(\mathrm{p}=0,7)$ the w-o-m communication is more effective and supported by the action of the leaders gives better results.

\section{Acknowledgments}

The work was supported by funds from the National Science Centre (NCN) through grant no. 2011/01/B/HS4/02740.

\section{References}

Bernerth J. (2004). Expanding our understanding of the change message. Human Resource Development Review, 3, 36-52.

Bommer W. H., Rich G. A., Rubin R. S. (2005). Changing attitudes about change: Longitudinal effects of transformational leader behavior on employee cynicism about organizational change. Journal of Organizational Behavior, 26, 733-753. 
Burt R. S. (2007). Secondhand brokerage: evidence on the importance of local structure for managers, bankers, and analysts. Academy of Management Journal, 50(1), 119-148.

Devos G., Buelens M., Bouckenooghe D. (2007). Contribution of Content, Context, and Process to Understanding Openness to Organizational Change: Two Experimental Simulation Studies, The Journal of Social Psychology, 147(6), 607-629.

Eby, L. T., Adams, D. M., Russell, J. E. A., Gaby, S. H. (2000). Perceptions of organizational readiness for change: Factor related to employees' reactions to the implementation of team-based selling. Human Relations, 53, 419-442.

Fleming, L., Mingo, S., Chen, D. (2007). Collaborative brokerage, generative creativity, and creative success. Administrative Science Quarterly, 52, 443-475.

Hendrick H. W., Kleiner B.M. (2001). Macroergonomics. An Introduction to Work System Design. Human Factors and Ergonomics Society.

Kowalska - Styczeń A. (2012). A cellular based model as a tool of the organizational culture change analysis, in Rebelo F., Soares M. Advances in Usability Evaluation: Part II, CRC Press / Taylor \& Francis, 200- 210.

Kotter, J. P., Cohen, D. S. (2002). The heart of change. Boston: Harvard Business School Press, 59-80.

Miller V. D., Johnson J. R., Grau J. (1994). Antecedents to willingness to participate in a planned organizational change. Journal of Applied Communication Research, 22(1), 59-80.

Oreg S. (2006). Personality, context, and resistance to organizational change. European Journal of Work and Organizational Psychology, 15, 73-101.

Pugh D. G., Bacon T. R. (2003). Winning behavior: what the smartest, most successful companies do differently, Amacom, a division of American Management Association. New York.

Todarita E., Strategies and tactics regarding change communication within organisations. Real example regarding communication change in an organization. Studies in Business and Economics, 2, 111-119.

Van Knippenberg B., Martin, L., Tyler T. (2006). Process-orientation versus outcomeorientation during organizational change: The role of organizational identification. Journal of Organizational Behavior, 27, 685-704.

Whelan-Berry, K. S., Gordon, J. R., Hinings, C. R. (2003). Strengthening organizational change processes: Recommendations and implications from a multi-level analysis. Journal of Applied Behavioral Science, 39, 186-207.

Wolfram S.(2002). A New Kind of Science. Wolfram Media, Inc.

Wolfram, S. (1984). Universality and complexity in cellular automata, Physica D, 10, $1-35$. 
